\title{
Comparative Study of the Protective Effect of Cola anomala and Coffea arabica Against Induced Toxicity in Rats
}

\author{
M-A. Angie Mbong ${ }^{1}$, F. L. Ebouel Edoun ${ }^{1}$, L. C. Manga Ngandi ${ }^{1}$, J. A. Fotso Youvop ${ }^{1}$, R. Orang Orang ${ }^{1}$, H. M. \\ Fotso Tienoue $^{1}$, F. Ngalla Nwang ${ }^{1}$, J. L. Ngondi ${ }^{1} \&$ J. Oben ${ }^{1}$ \\ ${ }^{1}$ Department of Biochemistry, Faculty of Science University of Yaounde 1, P.O. Box 812, Yaounde, Cameroon \\ Correspondence: Mary-Ann Angie Mbong, Department of Biochemistry, Faculty of Science University of \\ Yaounde 1, Cameroon. Tel: 237-670-310- 514. E-mail: mbongs2000@ yahoo.co.uk
}

Received: November 19, 2019 Accepted: July 8, $2020 \quad$ Online Published: July 20, 2020

doi:10.5539/jfr.v9n5p1

URL: https://doi.org/10.5539/jfr.v9n5p1

\begin{abstract}
This work was aimed at evaluating the effects of $C$. anomala and C. arabica on Methotrexate (MTX) induced metabolic disorders. For this, the aqueous extract (AE) of C. anomala and C. arabica were prepared and their polyphenols, flavonoids and alkaloids contents determined as well as their antiradical and total antioxidant capacity. An animal experimentation using female rats was carried out for 14 days. Rats were divided into 6 groups; a negative control group receiving water; a positive control group receiving $12 \mathrm{mg} / \mathrm{Kg} \mathrm{Bw}$ of MTX; four tests groups receiving $12 \mathrm{mg} / \mathrm{Kg}$ Bw of MTX and one of the extracts at a dose of $200 \mathrm{mg} / \mathrm{Kg} \mathrm{Bw}$ or $400 \mathrm{mg} / \mathrm{Kg}$ $\mathrm{Bw}$. At the end of the experiment, plasmas and hemolysates were prepared as well as liver and kidney homogenates for the evaluation of oxidative status (catalase, total protein and malondialdehyde (MDA)), liver toxicity (alanine amino transferase (ALT)) and renal toxicity (creatinine and urea) and lipid profile (triglycerides, total cholesterol and HDL-cholesterol). Weight gain in extract-treated rats was better with the C. anomala. Concerning oxidative status, MDA levels were generally lower in $C$. anomala-treated groups compared to $C$. arabica while catalase level was higher in C. anomala-treated rats. As for lipid profile, it is C. arabica that showed more or less better results. Both extracts led to an amelioration of toxicity markers compared to exclusive treatment with MTX. The results of this study suggest that $C$. anomala and $C$. arabica may reduce metabolic disorders associated with the intake of MTX during cancer treatment; $C$. anomala protecting better $C$. arabica.
\end{abstract}

Keywords: Cola anomala, Coffea Arabica, Methotrexate, metabolic disorders

\section{Introduction}

Caffeine is responsible for the stimulatory power of coffee and kola nut. The seeds of these two plants are highly consumed for this property. Traditionally, in western Africa, kola nut is consumed by mastication to fight physical and intellectual fatigue and to combat depression. It has also been recognised to ameliorate cognitive vigilance and performance (Bureau, 2013). The relationship between caffeine and cancer is very controversial. Some researchers have proven that the consumption of too much caffeine could affect the risk of developing cancer through various mechanisms. Still, other studies have shown the reduced risk of cancer with the consumption of coffee. The consumption of 3 to 4 cups of coffee per day is thought to reduce by $50 \%$ the risk of breast cancer in menopaused women and by $60 \%$ the risk of ovarian cancer. While for prostate cancer, this consumption could rather increase the risk of cancer development (Nehlig, 2012).

Recent research is geared at portraying the health benefits of these two plants that are attributable to the presence of bioactive secondary metabolites in their composition. It has been proven that the grains of Coffea arabica are an important source of biologically active metabolic molecules with many therapeutic properties. C. arabica contains phenolic compounds and their derivatives such as chlorogenic acid (Affonso et al., 2016) that are responsible for cardio protective, hepatoprotective, neuroprotective, nephroprotective properties. The presence of trigonelline in this plant has attributable antioxidant and antimicrobial properties (Najib, Ahmad \& Labadjo, 2015). Plants of the family of Sterculiaceae (in which we find kola nut species) contain many bioactive molecules amongst which we find alkaloids, flavonoids and polyphenols (Fabunmi \& Arotupin, 2015). Other species of kola nut have been proven to contain tannin that condenses into phlobaphenes that are responsible for the red color of the nuts. Xanthines (cafeine (triméthylxanthine) being the most abundant (2-3.5\%)), nitrogen 
containing molecules are the most represented groups of alkaloids. These xanthines have been proven to be responsible for their antidiarrhetic properties. Their polyphenols provide their strong antioxidant potential. In Asia, some decaffeinated extracts are thought to be responsible for their anti-inflammatory and chemopreventive properties through their action on androgenic receptors (Bureau, 2013). Studies carried out on Cola verticillata showed, antiproliferative and anti-toxic properties of this species (Mbong et al., 2013, 2014).

Chemotherapy is one of the most used therapies in the treatment of cancers. However, side effects associated with this treatment are usually the worries of patients (Tecza, Pamula-Pilat, Lanuszewska \& Grzybowska, 2015). Indeed, the toxicity of antineoplastic agents to rapidly replaceable cells such as bone marrow cells causes a large number of adverse effects in the body (Gorrini, Harris \& Mak, 2013). Free radical generation and lipid peroxidation are expressed as some complications of these effects. Methotrexate (MTX) is used as a chemotherapeutic agent to treat certain cancers and auto-immune diseases. Many studies have demonstrated its toxic effects involving most body organs like the liver, kidney and blood parameters. Its side effects could be controversially related to the production of ROS (Boussios, Pentheroudakis, Katsanos \& Pavlidi, 2012). Biologically, MTX causes lipid peroxidation indicated by high levels of Thiobarbituric acid reactive substances (TBARS). It also lowers levels of antioxidant enzymes such as catalase (CAT), superoxide dismutase (SOD), glutathione reductase indicating oxidative stress and thus decreasing the antioxidant defense systems responsible for its many side effects (Montasser et al., 2017). Oxidative stress-induced lipid peroxidation leads to the deterioration of membrane permeability barrier and loss of functions. It has also been reported that oxidized lipids are markers of pathologic mechanisms in a variety of disease states (Volinsky\& Kinnunen, 2013; Bochkov, Oskolkova \& Birukov, 2010).

Treatment with MTX has been reported to induce in rats critical changes in biological, biochemical and hematological markers (Saka \& Aouacheri, 2017).

Increasing attention is directed towards the role of plant bioactive molecules with antioxidants on the modulation of intracellular levels of reactive oxygen species resulting from cancer treatments (Saha et al., 2017). Plant bioactive compounds such as polyphenols, flavonoids and alkaloids can reduce oxidative stress through various mechanisms including trapping of these reactive oxygen species (Meher and Mishra, 2017). Cola anomala and Coffea arabica, two plants of the family of Malvaceaes and Rubiaceaes respectively, are widely produced in Cameroon and are used in particular for their stimulating properties. These plants have many bioactive compounds including polyphenols, flavonoids, alkaloids that give them their antioxidant properties (Najib, 2015). C. anomala is abundantly present in Cameroon but its consumption is more or less limited given that it is generally consumed by the elders and mainly during "traditional gatherings" compared to $C$. arabica that is more present in modern diets and is undoubtedly the most consumed beverage worldwide. Many biological activities have been attributed to both of these species and it was thought important to equally evaluate their possible biological benefits during treatment with a chemotherapeutic agent.

\section{Methods}

\subsection{In vitro Study}

This part of the study was carried out to determine the amounts of targeted bioactive molecules as well as the antioxidant potential of aqueous extracts of both plants.

\subsubsection{Collection of Biological Material}

The nuts of C. anomala were harvested in July 2017 in Bandjoun, Western region of Cameroon. The botanical identification was done in comparison to specimen $\mathrm{N}^{\mathrm{o}} 113$ collected in Nkongmenek corresponding to the sample C. anomala K.Schum at the Cameroon National Herbarium under voucher number 48706/HNC. After this, the nuts were washed, shade-dried, and powdered using a standard propeller crusher. The powder of roasted seeds of C. arabica was bought from a local seller in the Yaounde neighborhood in Cameroon.

\subsubsection{Preparation of Aqueous Extracts}

The extracts for this study were prepared depending on the plant sample. $C$. anomala was prepared by maceration. $300 \mathrm{~g}$ of powdered $C$. anomala nuts were macerated in $1.8 \mathrm{~L}$ of distilled water for $12 \mathrm{H}$ at room temperature. After the marceration period, the filtrate was recuperated using Whatman paper no 3, Whatman International Limited, Kent, England. The filtrate was then oven-dried at $50^{\circ} \mathrm{C}$ for $72 \mathrm{H}$. C. arabica on the other hand was prepared by infusion. $300 \mathrm{~g}$ of $C$. arabica powder was infused in hot water $\left(90{ }^{\circ} \mathrm{C}\right)$ for $10 \mathrm{~min}$. Following this, the mixture was filtered using Whatman paper $\mathrm{N}^{0} 3$, Whatman International Limited, Kent, England. The obtained filtrate was equally oven-dried at $50^{\circ} \mathrm{C}$ for $72 \mathrm{H}$. Both extracts were stored in polystyrene bags for further use. 


\subsubsection{Estimation of Bioactive Constituents and Antioxidant Potential}

Determination of total polyphenols

The Folin-Ciocalteu reagent method described by Singleton \& Rossi in 1965, was used to measure total phenolic content of the extracts. For this, $0.1 \mathrm{~mL}$ of extracts $(4 \mathrm{mg} / \mathrm{mL})$ was mixed with $0.75 \mathrm{~mL}$ of Folin-Ciocalteu $(0.2 \mathrm{~N})$ in opaque tubes. After $5 \mathrm{~min}$ at room temperature, $0.75 \mathrm{~mL}$ of sodium carbonate $(6 \%)$ was added. The tubes were mixed and incubated for another $90 \mathrm{~min}$ before measuring the optical densities at $725 \mathrm{~nm}$. Gallic acid was used as standard $(0-1000 \mu \mathrm{g} / \mathrm{mL})$. The test was done in triplicate for each extract and total phenol content was expressed in $\mathrm{mg}$ equivalent Gallic acid per gram dry weight of extract $(\mathrm{mgGAE} / \mathrm{g})$.

Determination of total flavonoids

The Aluminum chloride colorimetric method of Aiyegoro and Okoh, 2010 with slight modifications was exploited to assay the flavonoids content of the extracts. Briefly, $0.5 \mathrm{~mL}$ of various extracts $(4 \mathrm{mg} / \mathrm{mL})$ were added to $1.5 \mathrm{~mL}$ of methanol followed by addition of $0.1 \mathrm{~mL}$ of aluminum chloride $\left(\mathrm{AlCl}_{3}, 10 \%\right), 0.1 \mathrm{~mL}$ of potassium acetate $\left(\mathrm{CH}_{3} \mathrm{COOK}, 1 \mathrm{M}\right)$ and $2.8 \mathrm{~mL}$ of distilled water. The mixture was well shaken and incubated for $30 \mathrm{~min}$ at room temperature and its absorbance was measured at $415 \mathrm{~nm}$. Quercetin was used as standard $(0-1000 \mu \mathrm{g} / \mathrm{mL})$ and the total flavonoids content were expressed as mg equivalent quercetin per gram dry weight of extract (mgQuerE/g).

\section{Determination of alkaloids}

The amount of alkaloids in the extracts was determined using a modified method described by Singh et al (Singh, Vats, Suri, Shyram, Rangganathan \& Sriatharan, 2004). Summarily, $10 \mathrm{~mL}$ of $95 \%$ ethanol were added to $100 \mathrm{mg}$ of extract powder after which the mixture was centrifuged at $5000 \mathrm{rpm}$ for $10 \mathrm{~min}$. $1 \mathrm{~mL}$ of Iron-III Chloride $\left[\mathrm{FeCl}_{3}(0.025 \mathrm{M})+\mathrm{HCl}(0.5 \mathrm{M})\right]$ and $1 \mathrm{~mL}$ of ethanolic solution of 1,10 phenanthrolin $(0.05 \mathrm{M})$ were added to 1 $\mathrm{mL}$ of the obtained supernatant. The mixture obtained was incubated for $30 \mathrm{~min}$ at $70^{\circ} \mathrm{C}$. The absorbance of the red complex was measured at $510 \mathrm{~nm}$. Quinine was used as standard at different concentrations $(0-100 \mu \mathrm{g} / \mathrm{mL})$ and the total alkaloids content was expressed as $\mathrm{mg}$ equivalent quinine per gram dry weight of extract (mg QuiE/g).

Free radical scavenging activity on 1,1-diphenyl-2-picrylhydrazyl (DPPH)

The free radical scavenging activity of the extracts of $C$. anomala and $C$. arabica was evaluated using the method described in 2004 by Katalinié collaborators (Katalinié, Milos, Modun \& Boban, 2004). Briefly, $50 \mu \mathrm{L}$ of sample solution at different concentrations $(0.5$ to $7.5 \mathrm{mg} / \mathrm{mL})$ was added to $1.950 \mathrm{~mL}$ of fresh methanolic solution of DPPH $(3.2 \mathrm{mg} / 100 \mathrm{~mL})$, mixed and kept protected from light at $37{ }^{\circ} \mathrm{C}$ for $30 \mathrm{~min}$. The decrease of absorbance was recorded at $517 \mathrm{~nm}$. The percentage of DPPH inhibition was calculated as follows: DPPH Scavenging Effect $(\%)=\left(\left(\mathrm{A}_{0}-\mathrm{A}_{1}\right) 100 /\left(\mathrm{A}_{0}\right)\right)$, where $\mathrm{A}_{0}$ was the absorbance of the DPPH control solution and $\mathrm{A}_{1}$ was the absorbance of the assay (extract in presence of DPPH solution). The $\mathrm{IC}_{50}$ value was calculated by the table curve method.

\section{Total antioxidant capacity}

This activity was assessed by the phosphomolybdenum assay method as described by Prieto et al (Prieto, Pineda \& Aguilar, 1999). Briefly, an aliquot of $100 \mu \mathrm{L}$ of crude extract at different concentrations $(0.5$ to $7.5 \mathrm{mg} / \mathrm{ml})$ was combined with $1 \mathrm{~mL}$ of reagent $\left[\left(0.6 \mathrm{M}\right.\right.$ sulphuric acid $\left(\mathrm{H}_{2} \mathrm{SO}_{4}\right), 28 \mathrm{mM}$ sodium phosphate $\left(\mathrm{Na}_{3} \mathrm{PO}_{4}\right)$ and $4 \mathrm{mM}$ ammonium molybdate $\left.\left(\left(\mathrm{NH}_{4}\right)_{6} \mathrm{Mo}_{7} \mathrm{O}_{24} \cdot 4 \mathrm{H}_{2} \mathrm{O}\right)\right]$. The mixture was incubated at $95^{\circ} \mathrm{C}$ for 90 min after which it was cooled to room temperature. The variation in absorbance was measured at $765 \mathrm{~nm}$. Ascorbic acid was used as standard and the total antioxidant capacity was expressed in $\mathrm{mg}$ equivalent ascorbic acid per gram dry weight of extract (mg AAE/g).

\subsection{In vivo Study}

\subsubsection{Experimental Design and Protocol}

Wistar rats used for this study were reared in the animal house of the Laboratory of Nutrition and Nutritional Biochemistry (LNNB) of Department of Biochemistry, University of Yaounde 1, Cameroon. Female albino wistar rats of average weight $175 \pm 10 \mathrm{~g}$ were housed in a standard animal facility under controlled environmental conditions at room temperature. The rats were exposed to a $12 \mathrm{~h}$ light-dark cycle and received a standard chow diet and water ad libitum. For the experimentation, rats were kept in stainless steel standard cages and were acclimatized for 2 weeks in this environment before the conduction of experiments. Distilled water was used for the oral administration of the drug and plant extracts. The study protocol for laboratory animal use and care was legitimated by the Animal Ethics Committee of the Faculty of Sciences, University of Yaounde I, 


\section{Cameroon.}

Before the conduction of this experiment, the rats were weighed, divided into six groups of five rats each and labelled. Each group received a different treatment by oral administration (through esophageal gavage). The groups were:

Negative Control (NC): receiving distilled water by gavage

Positive Control (PC): receiving $12 \mathrm{mg} / \mathrm{kg} . \mathrm{Bw}$ of MTX + distilled water by gavage

Assay 1 (E1): receiving $12 \mathrm{mg} / \mathrm{kg}$.Bw of MTX $+200 \mathrm{mg} / \mathrm{kg}$.Bw C. anomala by gavage

Assay 2 (E2): receiving $12 \mathrm{mg} / \mathrm{kg}$.Bw of MTX $+400 \mathrm{mg} / \mathrm{kg}$.Bw C. anomala by gavage

Assay 3 (E3): receiving $12 \mathrm{mg} / \mathrm{kg}$.Bw of MTX $+200 \mathrm{mg} / \mathrm{kg} . \mathrm{Bw}$ C. arabica by gavage

Assay 4 (E4): receiving $12 \mathrm{mg} / \mathrm{kg}$.Bw of MTX $+400 \mathrm{mg} / \mathrm{kg}$.Bw C. arabica by gavage

Both extracts as well as the drug were dissolved in distilled water. All groups received a daily treatment in the morning. The cancer drug (MTX) was administered once per week. The rats were weighed on Days 1, 4, 8 and 12 during the experimentation period using an electronic weighing balance. After 14 days of experimentation, overnight fasted rats were sacrificed by cervical dislocation under slight anesthesia with diethyl-ether and blood was collected in EDTA tubes for preparation of plasma and hemolysates of erythrocytes. The liver and kidneys of each rat was collected, washed and rinsed with ice-cold saline solution $(0.9 \% \mathrm{NaCl})$. The homogenates were prepared at a concentration of $10 \%(\mathrm{w} / \mathrm{v})$ in normal saline $(0.9 \% \mathrm{NaCl})$. All prepared biological samples were stored at $-20^{\circ} \mathrm{C}$.

\subsubsection{Biochemical Analysis}

Measurement of lipid profile parameters

Total cholesterol (TC), triglycerides (TG) and HDL-cholesterol (HDL-c) concentrations were estimated using Chronolab kits according to the methods described by the manufacturer. The concentration of LDL-cholesterol was calculated using Friedewald's formula: LDL-cholesterol (LDL-c) $=$ TC- (HDL-c + TG/5) (Friedewald, Levy \& Fridrickson, 1972).

Evaluation of oxidative stress markers

Lipid peroxidation

In this method, thiobarbituric acid reactive substances (TBARS) were estimated by measuring the pink chromophore formed by the reaction of thiobarbituric acid with malondialdehyde (MDA) according to the method of Yagi (1976).

Catalase

The activity of catalase was assayed according to the method of Sinha (1972). The activity of this enzyme was expressed in $\mathrm{mM}$ hydrogen peroxide/min/mg of protein.

Total proteins

The level of total protein was assayed using the colorimetric method described by Gornall and collaborators (Gornall, Bardawill \& David, 1949). The optical density was recorded at $540 \mathrm{~nm}$. Bovine Serum Albumin (BSA) was used as standard at the concentration of $1 \mathrm{mg} / \mathrm{mL}$.

Evaluation of hepatic and renal markers of toxicity

Hepatic marker

The activity of a transaminase (Alanine amino transferase (ALT) was determined using a CHRONOLAB kit according to the method described by the manufacturer. Pyruvate was used as standard and the activity was estimated using a standard curve. The results were expressed in IU/mL.

Renal markers

The levels of creatinine and urea in plasma were estimated using standard kits (Chronolab) according to the method described by the manufacturer. The obtained results were expressed in $\mathrm{mg} / \mathrm{dL}$.

\subsubsection{Statistical Analysis}

Results were expressed as means \pm standard deviation. Statistical analysis was carried out using SPSS 20.0 for Windows. One way ANOVA (analysis of variance) followed by LSD (Least Significant Difference) and post hoc one factor was used to compare the means of different groups. Results were significant for $p \leq 0.05$. The 
Microsoft office excel software was used to treat the data and plot the graphs.

\section{Results}

\subsection{In vitro Study}

This study revealed the presence of phenolic compounds, flavonoids and alkaloids in the aqueous extracts of $C$. anomala and C. arabica (Table 1). Alkaloid levels were found to be more important compared to the other two families of bioactive compounds. The amounts of phenolic compounds were similar in both extracts while flavonoid content was higher in C. arabica and alkaloids higher in C. anomala.

Table 1. Bioactive content of C. anomala and C. Arabica

\begin{tabular}{llll}
\hline Extracts & Polyphenols (mg GAE/g DM) & Flavonoids (mg Quer E/g DM) & Alkaloids ( $\mu$ g Qui E/g DM) \\
\hline C. anomala & $1910 \pm 8.16$ & $94.38 \pm 0.17$ & $614.0 \pm 3.2$ \\
C. Arabica & $1928.89 \pm 5.67$ & $159.58 \pm 3.06$ & $441.1 \pm 5.6$ \\
\hline
\end{tabular}

The change in color from purple to yellow was found to be concentration dependent in both extracts for the scavenging of the DPPH free radical. Figure 1 is a representation of the inhibition percentages for both extracts. The extract of $C$. anomala exhibited best scavenging activity expressed by inhibition percentages varying from 7.34 to $64.14 \%$ against inhibition percentages varying from 11.98 to $39.25 \%$ for $C$. arabica. The $\mathrm{IC}_{50}$ value of $C$. anomala was found to be $4.01 \mathrm{mg} / \mathrm{mL}$ while the IC25 value for C. arabica was found to be $2.33 \mathrm{mg} / \mathrm{mL}$.

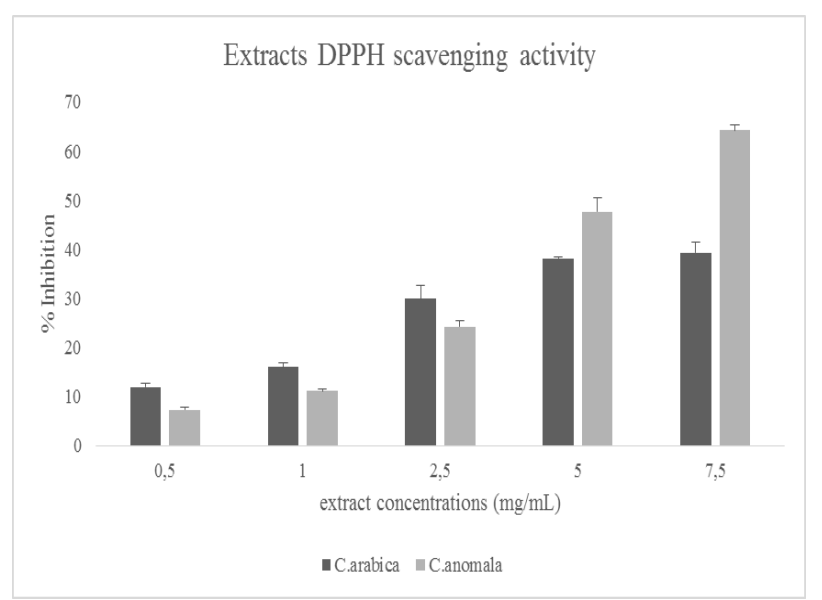

Figure 1. DPPH scavenging activity of extracts

As can be noticed in Figure 2, both extracts showed antioxidant activity and this was found to increase with increasing concentration of extract. For this study, the extract of $C$. anomala showed the highest reducing capacity at different concentrations compared to the extract of $C$. arabica. Depending on the extract concentration, this activity varied from 0.43 to $1.32 \mathrm{mg} \mathrm{mgAAE} / \mathrm{g} \mathrm{DM}$ for $C$. anomala extract against 0.16 to $1.17 \mathrm{mgAAE} / \mathrm{g}$ DM for $C$. arabica extract.

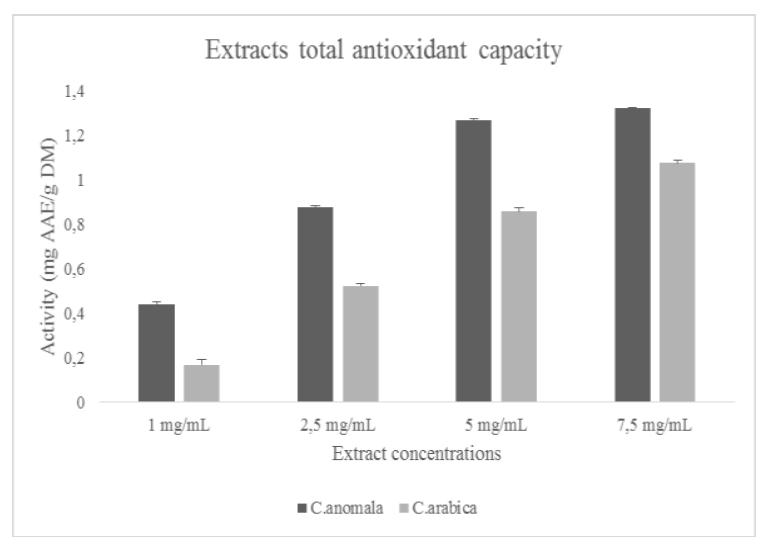

Figure 2. total antioxidant capacity of extracts plants 


\subsection{In vivo Study}

The results obtained (Figure 3), revealed that feeding animals with chow diet in association with a treatment with MTX reduced weight gain in rats since weight gain in the positive control group was found to be lower than for the negative control (Group not receiving any treatment). Both extracts were found ameliorate weight gain in rat treated with MTX. The treated rats that also received $C$. anomala were found to gain weight better than rats those receiving MTX and the extract of $C$. arabica. The weight gain for both extracts was not dose-dependent.

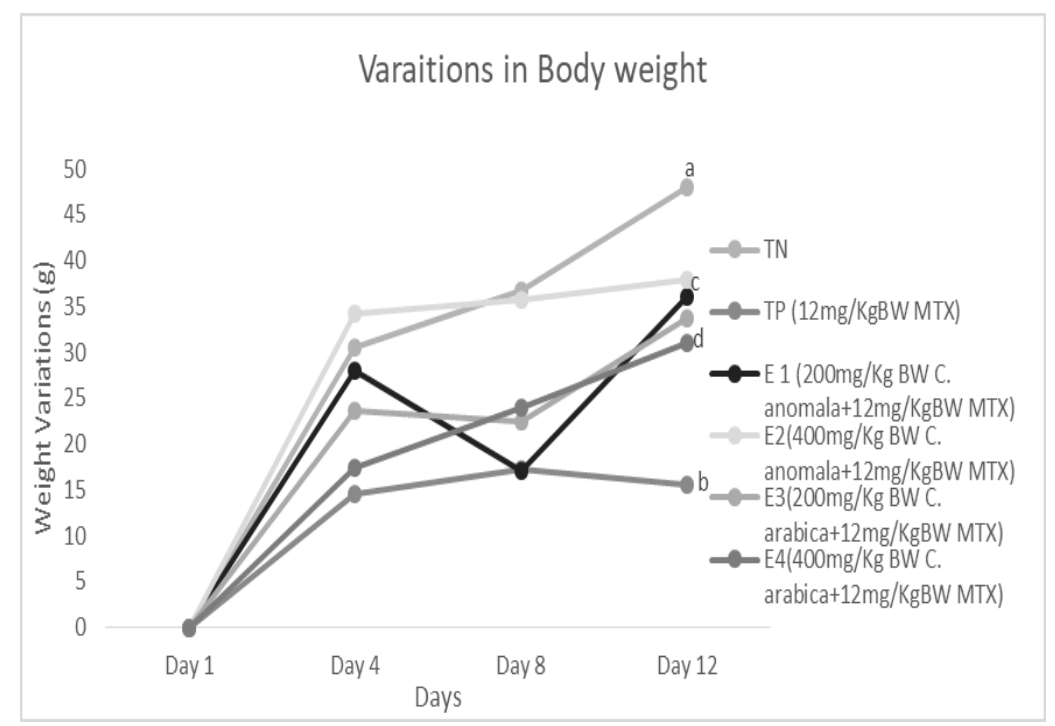

Figure 3. Effect of extracts on body weight of rats during Treatment

The results in Figure 4 show that there was no significant difference between the positive and negative control groups for the concentrations of TC, TG and HDL-c levels in plasma; only LDL-c was higher in the group receiving only MTX $(p<0,005)$. In the treated groups, a significant decrease of TC, HDL-c and TG and increase of LDL-c was observed in rats that were administered either of the aqueous extracts. Generally, so far as the lipid profile is concerned, treatment with MTX did not affect parameters while the administration of both aqueous extracts helped ameliorate these parameters especially for rats that received the higher dose of $C$. arabica.

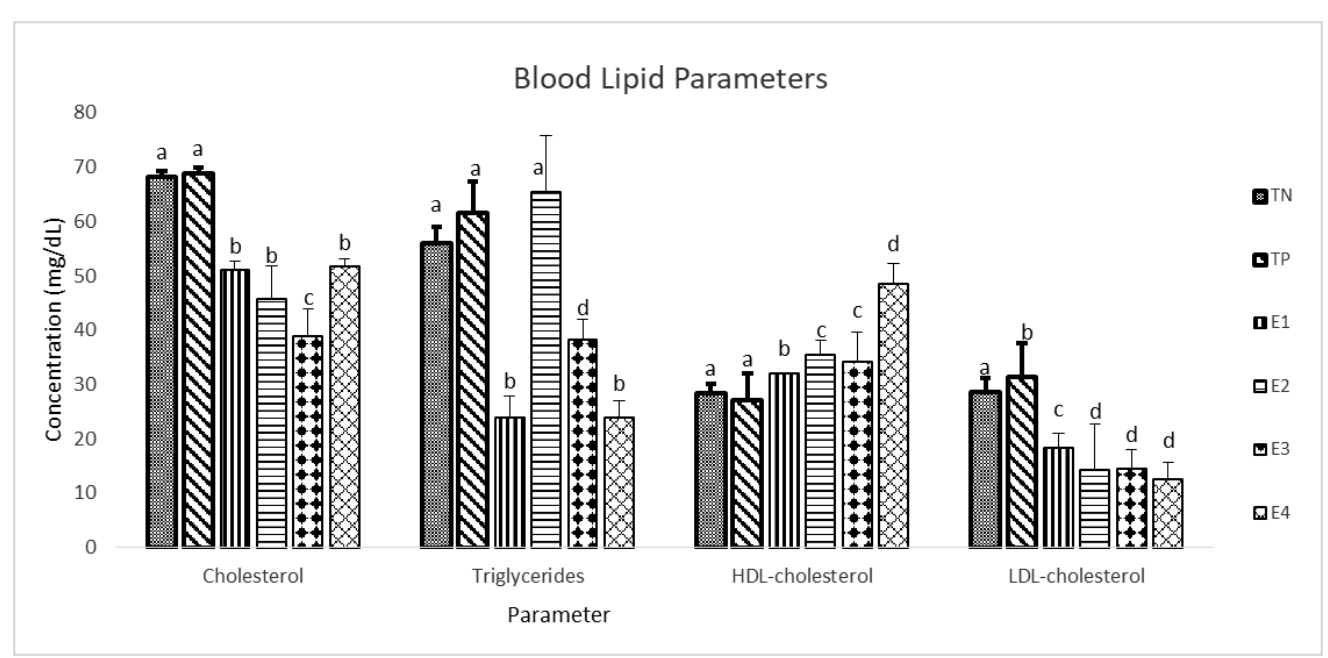

Figure 4. Effects of extracts of C. arabica and C. anomala on blood lipid paramters of experimental rats

The values are expressed as Mean \pm Standard deviation. TN : Negative Control (normal rats); TP: Positive Control (Cow diet $+12 \mathrm{mg} / \mathrm{Kg} \mathrm{MTX)}$; E1 : Cow diet $+12 \mathrm{mg} / \mathrm{Kg} \mathrm{MTX}+200 \mathrm{mg} / \mathrm{Kg} \mathrm{C}$. anomala ; E2 : Cow diet $+12 \mathrm{mg} / \mathrm{Kg}$ MTX $+400 \mathrm{mg} / \mathrm{Kg}$ C.anomala ; E3 : Cow diet $+12 \mathrm{mg} / \mathrm{Kg}$ MTX $+200 \mathrm{mg} / \mathrm{Kg}$ C.arabica ; E4 : Cow diet $+12 \mathrm{mg} / \mathrm{Kg}$ MTX $+200 \mathrm{mg} / \mathrm{Kg}$ C.arabica. The values affected with different letters (a, b, c, d) were significant. 
It can be observed on Figure 5 an increase in MDA levels $(p<0,05)$ in the positive control compared to the negative control group in kidney homogenates. In comparison with the positive control, the results obtained show $(p<0,05)$ reduction of plasmatic, hepatic and kidney levels of MDA in treated groups that received the extract of $C$. anomala. In the kidney of rats treated with extracts, MDA levels were reduced to values comparable to that of the control group that received no treatment. These levels were also found to be lower in the plasma of rats treated with the aqueous extract of $C$. anomala. These results were similar in the liver but for the lower dose of the aqueous extract of $C$. arabica.

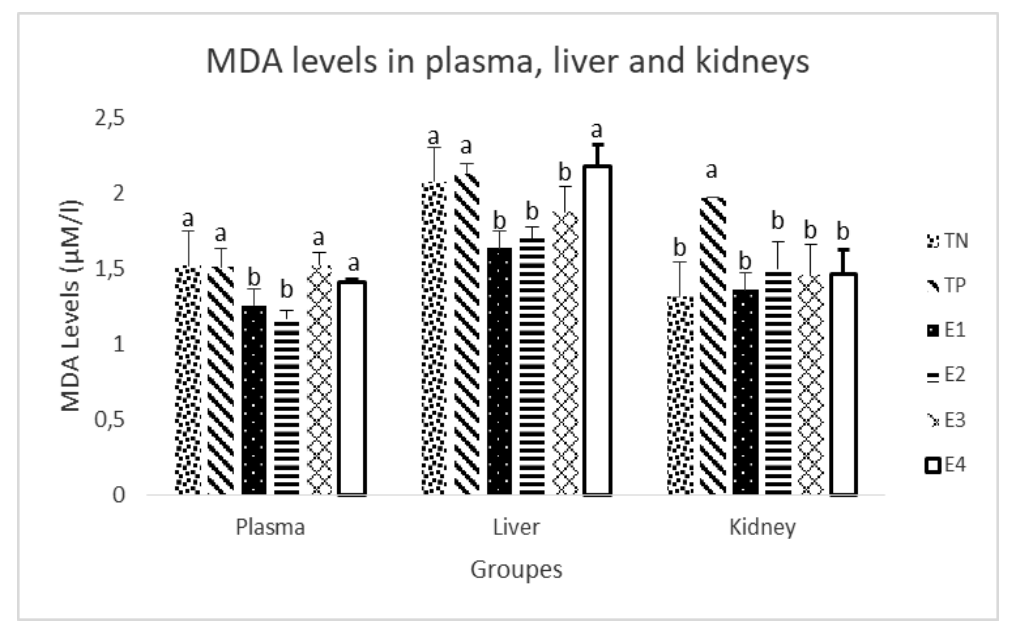

Figure 5. Effects of extracts on antioxidants markers

The values are expressed as Mean \pm Standard deviation. TN : Negative Control (normal rats); TP : Positive Control (Cow diet $+12 \mathrm{mg} / \mathrm{Kg} \mathrm{MTX)}$; E1 : Cow diet $+12 \mathrm{mg} / \mathrm{Kg} \mathrm{MTX}+200 \mathrm{mg} / \mathrm{Kg}$ C. anomala ; E2 : Cow diet $+12 \mathrm{mg} / \mathrm{Kg}$ MTX $+400 \mathrm{mg} / \mathrm{Kg} \mathrm{C}$. anomala ; E3 : Cow diet $+12 \mathrm{mg} / \mathrm{Kg}$ MTX $+200 \mathrm{mg} / \mathrm{Kg} \mathrm{C}$. arabica ; E4 : Cow diet $+12 \mathrm{mg} / \mathrm{Kg}$ MTX $+200 \mathrm{mg} / \mathrm{Kg} \mathrm{C}$. arabica. The values affected with different letters $(\mathrm{a}, \mathrm{b}, \mathrm{c}, \mathrm{d})$ were significant.

As concerns the activity of catalase as can be observed in Figure 6, treatment with MTX reduced the activity of catalase when compared to non-treated rats. Nonetheless, rats that received MTX treatment and either of the extracts at both doses saw their catalase activity boosted. It was at least noted that the extract of $C$. anomala showed better results when compared to $C$. arabica $(p<0,05)$.

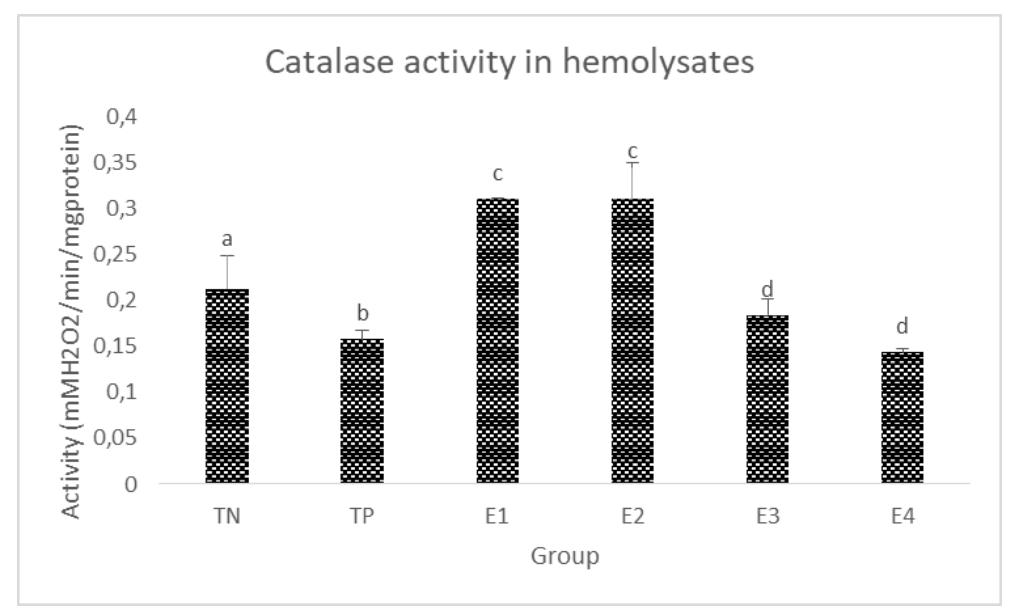

Figure 6. Effects of aqueous extracts of $C$. anomala and $C$. arabica on catalase activity in experimental rats

The values are expressed as Mean \pm Standard deviation. TN : Negative Control (normal rats); TP : Positive Control (Cow diet $+12 \mathrm{mg} / \mathrm{Kg} \mathrm{MTX);} \mathrm{E1} \mathrm{:} \mathrm{Cow} \mathrm{diet}+12 \mathrm{mg} / \mathrm{Kg} \mathrm{MTX}+200 \mathrm{mg} / \mathrm{Kg} \mathrm{C}$. anomala ; E2 : Cow diet $+12 \mathrm{mg} / \mathrm{Kg}$ MTX + $400 \mathrm{mg} / \mathrm{Kg}$ C.anomala ; E3 : Cow diet + $12 \mathrm{mg} / \mathrm{Kg}$ MTX + $200 \mathrm{mg} / \mathrm{Kg}$ C.arabica ; E4 : Cow diet $+12 \mathrm{mg} / \mathrm{Kg}$ MTX $+200 \mathrm{mg} / \mathrm{Kg}$ C.arabica. The values affected with different letters (a, b, c, d) were significant. 
Figure 7 is a representation of plasma ALT activity in experimental rats. The activity of this enzyme was found to be higher in the positive compared to the negative control group. The combination of MTX with extracts reduced the activity of this enzyme to levels comparable to non-treated rats. This was not true for the $200 \mathrm{mg}$ dose of $C$. anomala where activity was found to be comparable to the activity of the positive control group.

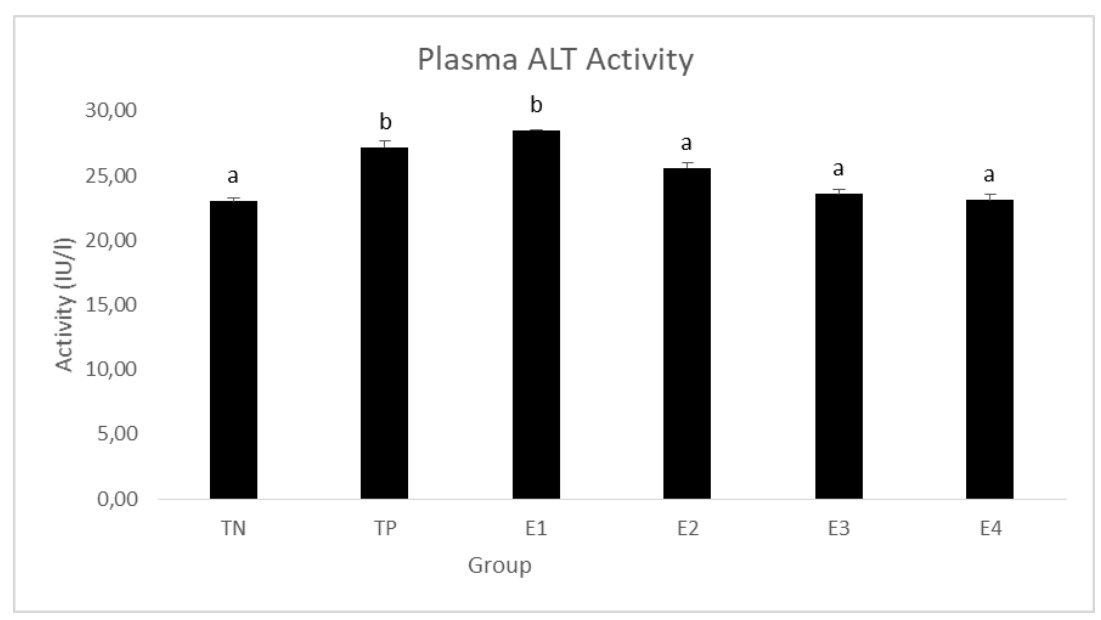

Figure 7. Effects of aqueous extracts of C. arabica and C. anomala on plasmatic Alanine amino-transferase (ALAT) levels in albino wistar rats

The values are expressed as Mean \pm Standard deviation. TN : Negative Control (normal rats); TP : Positive Control (Cow diet $+12 \mathrm{mg} / \mathrm{Kg} \mathrm{MTX)}$; E1 : Cow diet $+12 \mathrm{mg} / \mathrm{Kg} \mathrm{MTX}+200 \mathrm{mg} / \mathrm{Kg} \mathrm{C}$. anomala ; E2 : Cow diet $+12 \mathrm{mg} / \mathrm{Kg}$ MTX $+400 \mathrm{mg} / \mathrm{Kg}$ C.anomala ; E3 : Cow diet $+12 \mathrm{mg} / \mathrm{Kg}$ MTX $+200 \mathrm{mg} / \mathrm{Kg} \mathrm{C}$.arabica ; E4 : Cow diet $+12 \mathrm{mg} / \mathrm{Kg}$ MTX $+200 \mathrm{mg} / \mathrm{Kg}$ C.arabica. The values affected with different letters (a, b, c, d) were significant.

In Figure 8, it can be seen that the level of plasmatic creatinine was more important in the positive control group compared to the negative control $(p<0,05)$. Treated rats that equally received the aqueous extract of $C$. anomala had creatinine levels that were lower than for the negative control $(p<0,05)$ while $C$. arabica group values were more or less similar to the negative control group of rats $(p<0,05)$.

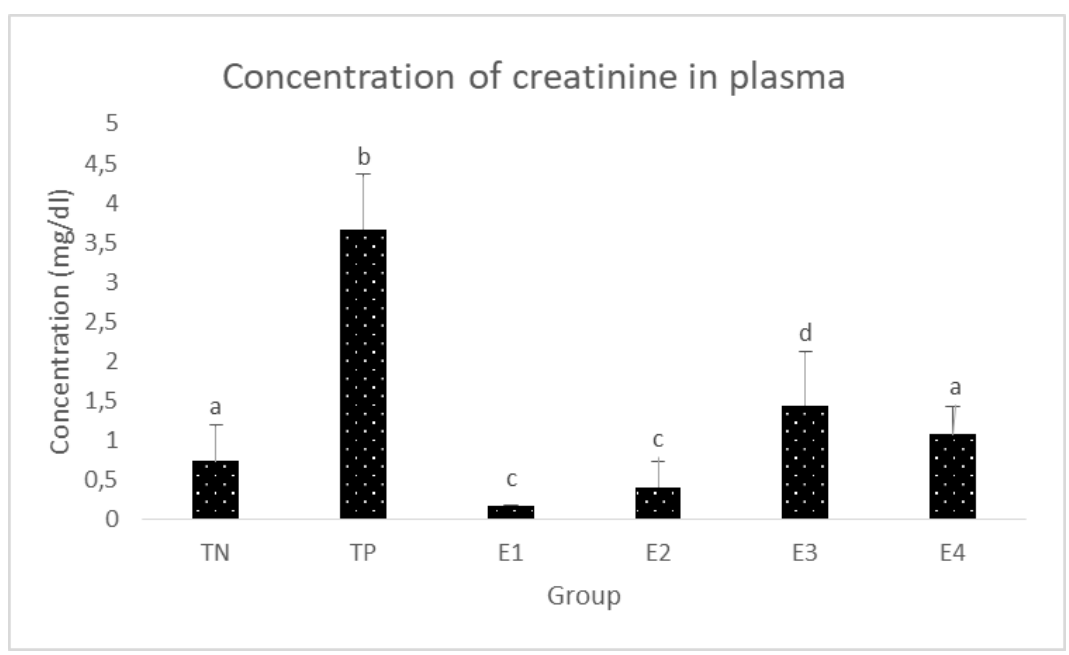

Figure 8. Effects of aqueous extracts of C. anomala and C. arabica on creatinine levels of plasma in experimental rats

The values are expressed as Mean \pm Standard deviation. TN: Negative Control (normal rats); TP: Positive Control (Cow diet $+12 \mathrm{mg} / \mathrm{Kg} \mathrm{MTX)}$; E1 : Cow diet $+12 \mathrm{mg} / \mathrm{Kg} \mathrm{MTX}+200 \mathrm{mg} / \mathrm{Kg} \mathrm{C}$. anomala ; E2 : Cow diet $+12 \mathrm{mg} / \mathrm{Kg} \mathrm{MTX}+400 \mathrm{mg} / \mathrm{Kg} \mathrm{C}$. anomala ; E3 : Cow diet $+12 \mathrm{mg} / \mathrm{Kg} \mathrm{MTX}+200 \mathrm{mg} / \mathrm{Kg} \mathrm{C}$. arabica ; E4 : Cow diet $+12 \mathrm{mg} / \mathrm{Kg}$ MTX $+200 \mathrm{mg} / \mathrm{Kg} \mathrm{C}$. arabica. The values affected with different letters $(\mathrm{a}, \mathrm{b}, \mathrm{c}, \mathrm{d})$ were significant. 
An increase in plasmatic urea levels was also observed after administration of MTX compared to the group that did not receive MTX (Figure 9). The extract-treated groups showed reduced levels of urea in the plasma of treated rats and the obtained values were comparable to those of the negative control. However, the dose 200 $\mathrm{mg} / \mathrm{kg}$.Bw of $C$. arabica showed a better reduction of urea level compared to all the other groups.

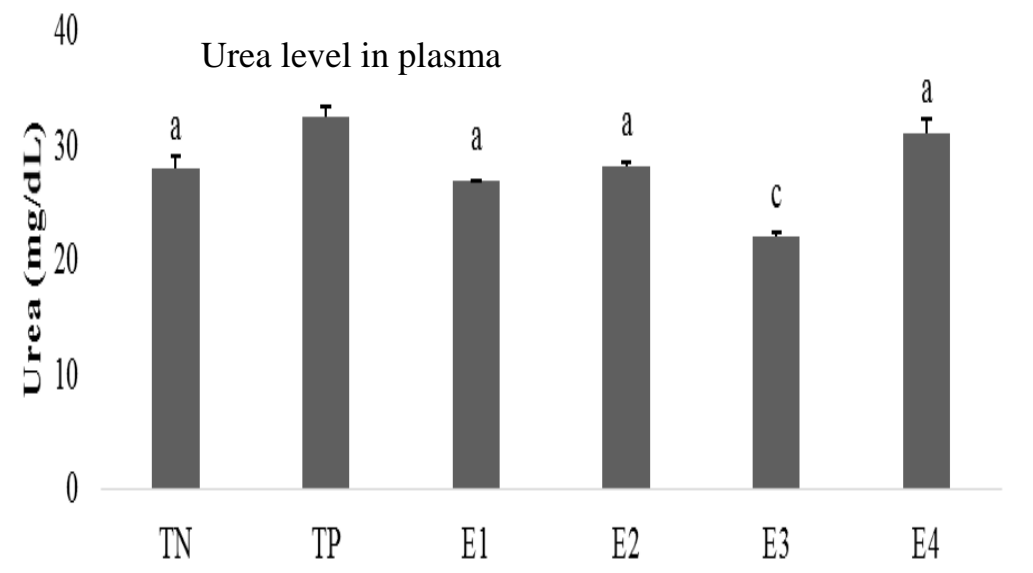

Figure 9. Effects of the aqueous extracts of $C$. arabica and C. anomala on the urea concentrations of the plasma of experimental rats

The values are expressed as Mean \pm Standard deviation. TN: Negative Control (normal rats); TP: Positive Control (Cow diet $+12 \mathrm{mg} / \mathrm{Kg} \mathrm{MTX)}$; E1 : Cow diet $+12 \mathrm{mg} / \mathrm{Kg} \mathrm{MTX}+200 \mathrm{mg} / \mathrm{Kg} \mathrm{C}$. anomala ; E2 : Cow diet $+12 \mathrm{mg} / \mathrm{Kg} \mathrm{MTX}+400 \mathrm{mg} / \mathrm{Kg} \mathrm{C}$. anomala ; E3 : Cow diet $+12 \mathrm{mg} / \mathrm{Kg}$ MTX $+200 \mathrm{mg} / \mathrm{Kg} \mathrm{C}$. arabica ; E4 : Cow diet $+12 \mathrm{mg} / \mathrm{Kg}$ MTX $+200 \mathrm{mg} / \mathrm{Kg} \mathrm{C}$. arabica. The values affected with different letters $(\mathrm{a}, \mathrm{b}, \mathrm{c}, \mathrm{d})$ were significant.

\section{Discussion}

Weight loss is one of the most observed complications of chemotherapy due to an increase in treatment-related side effects (Bonomi, Batus, Fidler \& Borgia, 2017). The results showed that even if weight gain in extract treated rats was not comparable to weight gain in non-treated rats, rats that received extracts in addition to MTX had better weight evolution compared to those that received MTX exclusively, suggesting a protective effect of the extracts against the limitations of weight gain induced by MTX. MTX is able to bind to neuropeptide Y (NPY) to decrease drug resistance by cancer cells (Böhme, Krieghoff \& Beck-Sickinger, 2016). However NPY is a peptide neurotransmitter involved in the induction of food intake. Its association with MTX leads to a decrease in its activity resulting in a decrease in dietary intake, which is a direct consequence on weight gain in the positive control group compared to the negative control. On the other hand, the alkaloids present in our extracts with their stimulating action, could stimulate the neurotransmitter system and thus modulate the inhibitory action exerted by MTX on the NPY. Hussain et al. (2018) have shown that alkaloids thanks to their antioxidant and anti-amyloid as well as acetylcholine esterase inhibition, improve the functioning of the neurotransmitter system.

The antioxidant potential of each extract was evaluated using two methods: total antioxidant capacity (TAC) and scavenging of DPPH free radical. Both plant extracts were found to scavenge the DPPH free radical and reduce molybdate even if these activities varied according to the plant extracts. The activities observed could be linked to the presence of bioactive compounds that were found to be present in the prepared aqueous extracts. It has been demonstrated that polyphenols, flavonoids and alkaloids are important constituents that serve as powerful antioxidants due to the hydrogen-donating ability of their hydroxyl groups as well as their ability to donate electrons to stop the free radicals production involved in oxidative stress (Lin et al., 2016; Gulçin et al., 2010). For both tests, the extract of $C$. anomala was found to have a better antioxidant potential when compared to the extract of $C$. arabica. The amount of polyphenol was similar in both extracts while the amount of flavonoids was more important in the $C$. arabica extract and alkaloids more important in the extract of $C$. anomala. The activity of bioactive compounds depends more on the hydrogen and electron donating capacity than the amount of bioactive compound present in the sample. From this it could be thought that the antioxidant potential that was more important in $C$. anomala is due to the higher amount of alkaloids or due to bioactive compounds that are more active. This activity could also be due to the presence of other bioactive compounds that were not evaluated in this work. The above mentioned findings indicate that both $C$. anomala and C. arabica are sources 
of phenolics, flavonoids and alkaloids and may therefore play a critical role as a singlet oxygen quencher and free radical scavenger to reduce molecular damage in the cell.

There is evidence that diseases such as cancer multiforms are highly related to oxidative stress. Also, oxidative stress may have a role in therapeutic mechanisms of anticancer agents like MTX. MTX decreases the effectiveness of the antioxidant defense system resulting in an increase in oxidative stress and MTX-induced oxidative stress has been observed in tumor tissues (Kolli, Nataraja, Isaac, Selvakumar \&Abraham, 2014; El-sheikh, Morsy \& Hamouda, 2016; Mahmoud, Hussein, Hozayen \& El-Twab, 2017). Therefore, preventing oxidative damage and increasing antioxidants, could be an asset during cancer treatments. In this study, we investigated the influence of MTX treatment on the antioxidant defense system by evaluating the MDA levels and catalase activity in rats treated with MTX and MTX combined with either of our extracts. Associating both plants with MTX treatment reduced the MDA levels and increased catalase activity in experimental rats. It has been proven that the use of MTX induces lipid peroxidation with liberation of high levels of reactive oxygen and nitrogen species. The use of MTX has also been linked to the lowering of the activity of antioxidant enzymes such as catalase, superoxide dismutase and glutathione reductase (Montasser, Saleh, Ahmed-Farid, Saad \& Mohamed-Assem, 2017). It can also cause an increase in the activity of these enzymes due to increased utilization for the scavenging of ROS generated due to oxidative stress (Saravanan, Ponmurugan, Sathiyavathi, Vadivukkarasi \& Sengottuvelu, 2013). Catalase activity in this study was found to be lower in rats treated exclusively with MTX, meaning this treatment caused a reduction in its activity. The association of extracts to the MTX treatment protected the functioning of this enzyme as in this rats its activity was found to be higher. This mechanism can be further explained by the levels of MDA that was not found to be higher in rats that received MTX in combination with an extract compared to those that received only MTX. As a matter of fact, associating MTX with $C$. anomala provided lower levels of MDA levels for higher catalase activity (this was not the case with $C$. arabica where MDA levels were similar but catalase activity was higher than for the MTX exclusively treated group). From these results, the antioxidant defense system was found to be more protected by $C$. anomala than $C$. arabica in experimental rats. These results correspond to the in vitro results in this study where we found that the scavenging of DPPH free radical and the reduction of molybdate was more important with the aqueous extracts of $C$. anomala compared to the aqueous extract of $C$. arabica.

The role of bioactive molecules in the protection of the antioxidant defense system as is the case with $C$. anomala and $C$. arabica is of great importance in protecting biological systems from the deleterious effects of reactive oxygen and nitrogen species that are generated during cancer treatment with a chemotherapeutic drug. These reactive species have been found to increase cell damage by influencing the activity of the mitochondrial respiratory chain, causeing inflammation, all leading to the damage of other biological molecules, like proteins and DNA (Lea, Tung \& Zhou, 2015; Halliwell, 2002). All these are capable of leading to disorders in metabolic pathways. In this study was also evaluated the effect of our extracts on MTX-induced lipid metabolism disturbances by measuring some parameters of the lipid profile. MTX is a drug that is known to cause hepatic steatosis (Shetty et al., 2017) that leads to modifications in blood lipid parameters. Treatment with MTX did not affect these parameters except for LDL-cholesterol that was found to be increased ( $p<0.05)$. It could be that the treatment was not long enough for disorders in these parameters to be observed. This interpretation can be supported by the fact that rats that received MTX in combination with extracts were found to have parameters that were better than those of rats that did not receive any treatment. The decrease in TG and LDL-cholesterol as can be observed in Figure 4 may be due to the activation of hepatic lipase which hydrolyzes TG-rich lipoproteins (LDL-c, VLDL-c) thus causing an increase in HDL-c (Abdulazeez, 2011). Also, decrease in total cholesterol may be due to a possible inhibition of the enzyme HMG-CoA reductase; the inhibition of this enzyme has been reported to prevent the production of hepatic cholesterol (Ahmadi, Ghorbanhagho \& Argani, 2017). Comparing both extracts, showed that the aqueous extract of $C$. arabica ameliorated lipid parameters better than $C$. anomala especially with the $400 \mathrm{mg}$ dose $(\mathrm{p}<0.05)$.

The evaluation of protein, urea and creatinine levels and the activity of ALT were carried out to determine the level of damage that MTX treatment could have caused on the liver and kidneys of experimental rats.

The results showed that the total protein level was not different between groups. However, a significantly ( $\mathrm{p}$ $<0.05)$ elevated plasma ALT activity was observed in the group that received only MTX. Montasser and collaborators in 2017 also showed that treatment with MTX elevated plasma levels of ALT indicating liver toxicity since the release of this enzyme into the blood stream is an indicator of liver damage due to the destruction of liver cells through the loss of the functional integrity of hepatocytes leading to a leakage of its content into the blood stream (Montasser, Saleh, Ahmed-Farid, Saad \& Mohamed-Assem, 2017). Both doses of $C$. arabica and the $400 \mathrm{mg}$ dose of $C$. anomala helped reduce ALT to levels that were comparable to that of 
non-treated rats. It can thus be suggested that the aqueous extract of $C$. arabica protected the liver more than $C$. anomala. In this experimentation, MTX also increased the levels of creatinine and urea both indicators of renal toxicity. Harms et al. (2017) also carried out a study where plasma creatinine and urea levels were high after treatment with MTX (Harms, Khawaja, Taylor, Han \& Mrug, 2017). As can be observed in Figures 8 and 9, the levels of these metabolic wastes were found to be lowered by associating MTX with either of the extracts. From these results, it can be suggested that both extracts improved glomerular filtration there by reducing the deleterious effects of MTX on the kidney. It is thought that this drop could be promoted by phenolic compounds contained in these extracts through their ability to protect the kidney from MTX-induced oxidative stress (Ahmed, Zaki \& Nabil, 2015). Creatinine was lower in C. anomala-treated groups while urea was lower only for the $200 \mathrm{mg}$ dose of C. arabica.

\section{Conclusion}

The aim of this work was to compare the ability of $C$. anomala and $C$. arabica to protect rats against MTX-induced toxicity. Concerning the parameters evaluated in this study, both aqueous extracts of $C$. anomala and $C$. arabica protected against metabolic disorders that were generated by MTX. It appears that, these extracts contain important amounts of bioactive compounds with good scavenging and reducing capacity. These compounds helped increase antioxidant status of experimental rats; the consequence of this being the protection of rats exposed to MTX from renal and liver damage as well as improved lipid metabolism parameters. To a certain level, $C$. anomala protected the rats better against these deleterious effects compared to $C$. arabica at least for the two doses (200 and $400 \mathrm{mg} / \mathrm{kg} . \mathrm{Bw})$ and for the parameters investigated. All doses exhibited hepatoprotective and nephroprotective effects.

\section{References}

Abdulazeez, M. (2011). Effect of Peristrophe bicalyculata on lipid profile of P-407-induced hyperlipidemic Wistar rats. Journal of Medicinal Plants Research, 5(4), 490-494.

Affonso, R., Voytena, A., Fanan, S., Pitz, H., Coelho, D., Horstmann, A., ... Maraschin, M. (2016). Phytochemical Composition, Antioxidant Activity, and the Effect of the Aqueous Extract of Coffee (Coffea arabica L.) Bean Residual Press Cake on the Skin Wound Healing. Oxidative Medicine and Cellular Longevity. https://doi.org/10.1155/2016/1923754

Ahmadi, Y., Ghorbanihaghjo, A., \& Argani, H. (2017). The effects of statins on the organs: similar or contradictory?. Journal of Cardiovascular Thoracic Research, 9(2), 64-70. https://doi.org/10.15171/jcvtr.2017.11

Ahmed, W., Zaki, A., \& Nabil, T. (2015). Prevention of methotrexate-induced nephrotoxicity by concomitant administration of garlic aqueous extract in rat. Turkish Journal of Medical Science, 45, 507-516. https://doi.org/10.3906/sag-1408-121

Aiyegoro, A., \& Okoh, I. (2010). Preliminary phytochemical screening and In vitro antioxidant activities of the aqueous extract of Helichrysum longifolium DC. BMC Complementary and Alternative Medicine. https://doi.org/10.1186/1472-6882-10-21

Bochkov, V. N., Oskolkova, O. V., Birukov, K. G., Levonen, A. L., Binder, C. J., \& Stôckl, J. (2010). Generation and biological activities of oxidized phospholipids. Antioxidant \& Redox Signaling, 12, 1009-1059. https://doi.org/10.1089/ars.2009.2597

Böhme, D., Krieghoff, J., \& Beck-Sickinger, G. (2016). Double Methotrexate-Modified Neuropeptide Y Analogues Express Increased Toxicity and Overcome Drug Resistance in Breast Cancer Cells. Journal of Medical Chemistry, 59(17), 3409-3417. https://doi.org/10.1021/acs.jmedchem.6b00043

Bonomi, P., Batus, M., Fidler, M., \& Borgia, A. (2017). Practical and theoretical implications of weight gain in advanced non-small cell lung cancer patients. Annals of Translational Medicine, 5(6), 152. https://doi.org/10.21037/atm.2017.03.20

Boussios, S., Pentheroudakis, G., Katsanos, K., \& Pavlidis, N. (2012). Systemic treatment-induced gastrointestinal toxicity: incidence, clinical presentation and management. Annals of Gastroenterology, 25, 106-118.

Bureau, L. (2013). Kola. Phytothérapie, 11, 126-129. https://doi.org/10.1007/s10298-013-0769-7

Derong, L., Mengshi, X., Jingjing, Z., Zhuohao, L., Baoshan, X., Xindan, L., ... Saiyan, C. (2016). An Overview of Plant Phenolic Compounds and Their Importance in Human Nutrition and Management of Type 2 Diabetes. Molecules, 21, 1374-1393. https://doi.org/10.3390/molecules21101374 
El-Sheikh, A. A., Morsy, M. A., \& Hamouda, A. H. (2016). Protective mechanisms of thymoquinone of methotrexate-induced intestinal toxicity in rats. Pharmacognosy Magazine, 12(1), 76-81. https://doi.org/10.4103/0973-1296.176106

Fabunmi, B., \& Arotupin, J. (2015). Proximate Mineral and Antinutritional Composition of Fermented Slimy Kolanut (Cola verticillata) Husk and White Shell. British Journal of Applied Science and Technology, 6(5), 550-556. https://doi.org/10.9734/BJAST/2015/8464

Friedewald, W., Levy, R., \& Fredrickson, D. (1972). Estimation of concentration of low density lipoproteins in plasma without use of ultracentrifuge. Clinical chemistry, 18, 449-502. https://doi.org/10.1093/clinchem/18.6.499

Gornall, G., Bardawill, J., \& David, M. (1949). Determination of serum proteins by means of the biuret reaction. Journal of Biological Chemistry, 177(2), 751-766.

Gorrini, C., Harris, S., \& Mak, W. (2013). Modulation of oxidative stress as an anticancer strategy. Nature Reviews Drug Discovery, 12, 931-947. https://doi.org/10.1038/nrd4002

Halliwell, B. (2002). Effect of diet on cancer development: Is oxidative DNA damage a biomarker. Free Radical Biology and Medicine, 32, 968-974. https://doi.org/10.1016/S0891-5849(02)00808-0

Harms, J., Khawaja, A., Taylor, M., Han, X., \& Mrug, M. (2017). Recovery of methotrexate-induced anuric acute kidney injury after glucarpidase therapy. SAGE Open Medical Case Reports, 5, 1-4. https://doi.org/10.1177/2050313X17705050

Hussain, G., Rasul, A., Anwar, H., Aziz, N., Razzaq, A., Wei, W., ... Li, X. (2018). Role of Plant Derived Alkaloids and Their Mechanism in Neurodegenerative Disorders. International Journal of Biological Sciences, 14(3), 341-357. https://doi.org/10.7150/ijbs.23247

Ilhami, G., Ercan, B., Hilal, Ş., Mine, B., \& Ahmet, C. G. (2010). Polyphenol contents and antioxidant activity of lyophilized aqueous extract of propolis from Erzurum. Turkey Food and Chemical Toxicology, 48(8), 2227-2238. https://doi.org/10.1016/j.fct.2010.05.053

Katalinié, V., Milos, M., Modun, D., Musi, I., \& Boban, M. (2004). Antioxidant effectiveness of selected wines in comparison with (+) - catechin. Food Chemistry, 86, 593-600. https://doi.org/10.1016/j.foodchem.2003.10.007

Kolli, V. K., Natarajan, K., Isaac, B., Selvakumar, D., \& Abraham, P. (2014). Mitochondrial dysfunction and respiratory chain defects in a rodent model of methotrexate-induced enteritis. Human Experimental Toxicology, 33(10), 1051-1065. https://doi.org/10.1177/0960327113515503

Lea, A., Tung, J., \& Zhou, A. (2015). Flexible Efficient Binomial Mixed Model for Identifying Differential DNA Methylation in Bisulfite Sequencing Data. PLoS Genetics, 11, e1005650. https://doi.org/10.1371/journal.pgen.1005650

Mahmoud, A. M., Hussein, O. E., Hozayen, W. G., \& Abd El-Twab, S. M. (2017). Methotrexate hepatotoxicity is associated with oxidative stress, and downregulation of PPARgamma and Nrf2: Protective effect of 18betaGlycyrrhetinic acid. Chemical Biological Interactions, 270, 59-72. https://doi.org/10.1016/j.cbi.2017.04.009

Mbong M-A., Azantsa, G. B., Braicu, C., Ioana, N., Alexandru I., Ngondi, L. J., \& Oben, J. E., (2013) Antiproliferative effect of hydroethanolic extracts of seeds of Cola verticillata and leaves of Solanum scabrum. Biology and Medicine, 5, 46-57.

Meher, K., \& Mishra, P. (2017). Radiation oxidative stress in cancer induction and prevention. Journal of Radiation and Cancer Research, 8, 44-52. https://doi.org/10.4103/jrcr.jrcr_10_17

Montasser, S., Saleh, H., Ahmed-Farid, A., Saad, A., \& Mohamed-Assem, S. (2017). Protective effects of Balanites aegyptiaca extract, Melatonin and Ursodeoxycholic acid against hepatotoxicity induced by Methotrexate in male rats. Asian Pacific Journal of Tropical Medicine, 10(6), 557-565. https://doi.org/10.1016/j.apjtm.2017.06.003

Najib, A., Ahmad, R., \& Labadjo, S. (2015). Chemoprofiling and determination of caffeine content on Arabica Coffee (Coffea Arabica L.). Journal of chemical and pharmaceutical research, 7(12), 374-377.

Nehlig, A. (2012). Effets physiologiques du café et santé humaine. Cahiers Agricultures Journal, 21, 197-207. https://doi.org/10.1684/agr.2012.0549 
Prieto, P., Pineda, M., \& Aguilar, M. (1999). Spectrophotometric quantitation of antioxidant capacity through the formation of a phosphomolybdenum complex: specific application to the determination of vitamin $\mathrm{E}$. Analytical Biochemistry, 269, 337-341. https://doi.org/10.1006/abio.1999.4019

Mbong, M-A., Djiokeng, P. G., Ntentie, F. R., Dimodi, H., Ngondi, J. L., \& Oben, E. J. (2014). Protective Effect of Hydroethanolic Extracts of Solanum scabrum and Cola verticillata Against Cyclophosphamide Induced Toxicity in Female Rats. Journal of Food Research, 3(3), 18-30. https://doi.org/10.5539/jfr.v3n3p18

Saha, S., Lee, S., Won, J., Choi, H., Kim, K., Yang, G., ... Cho, S. (2017). Correlation between Oxidative Stress, Nutrition, and Cancer Initiation. International Journal of Molecular Sciences, 18, 1544. https://doi.org/10.3390/ijms18071544

Saka, S., \& Aouacheri, O. (2017). The Investigation of the Oxidative Stress-Related Parameters in High Doses Methotrexate-Induced Albino Wistar Rats. Journal of Bioequivalence and Availability, 9, 372-376. https://doi.org/10.4172/jbb.1000327

Saravanan, G., Ponmurugan, P., Sathiyavathi, M., Vadivukkarasi, S., \& Sengottuvelu, S. (2013). Cardioprotective activity of Amaranthus viridis Linn: effect on serum marker enzymes, cardiac troponin and antioxidant system in experimental myocardial infarcted rats. International Journal of Cardiology, 165(3), 494-498. https://doi.org/10.1016/j.ijcard.2011.09.005

Shetty, A., Cho, W., Alazawi, W., \& Syn, K. (2017). Methotrexate Hepatotoxicity and Impact of Nonalcoholic Fatty Liver Disease. American Journal of Medical Science, 354(2), 172-181. https://doi.org/10.1016/j.amjms.2017.03.014

Singh, S., Vats, P., Suri, S., Shyram, R., Rangganathan, S., \& Sriatharan, K. (2004). Effect of an antidiabetic extract of catharantus roseus on enzymatic activities in spectozotocin induced diabetes rats. Journal of Ethnopharmacology, 76, 269-277. https://doi.org/10.1016/S0378-8741(01)00254-9

Singleton, V., \& Rossi, J. (1965). Colorimetry of total phenolics with phosphomolydic-phosphotungstic acid reagents. American Journal of Enology Viticulture, 16, 144-158.

Sinha, K. (1972). Colorimetric Assay of Catalase. Analytical Biochemistry, 47, 389-394. https://doi.org/10.1016/0003-2697(72)90132-7

Tecza, K., Pamula-Pilat, J., Lanuszewska, J., \& Grzybowska, E. (2015). Pharmacogenetics of FAC chemotherapy side effects in breast cancer patients. Hereditary Cancer in Clinical Practice, 13, A10. https://doi.org/10.1186/1897-4287-13-S2-A10

Volinsky, R., \& Kinnunen, P. K. J. (2013). Oxidized phosphatidylcholines in membrane-level cellular signaling: From biophysics to physiology and molecular pathology. Federation of European Biochemistry Societies Journal, 280, 2806-2816. https://doi.org/10.1111/febs.12247

Yagi, K. (1976). Simple Fluorometric Assay for lipoperoxyde in blood plasma. Biochemistry Medicine, 15, 212-216. https://doi.org/10.1016/0006-2944(76)90049-1

Zimmerman, C., Clemens, L., Duryee, J., Sarmiento, C., Chiou, A., Hunter, D., ... Anderson, R. (2017). Direct antioxidant properties of methotrexate: Inhibition of malondialdehyde-acetaldehyde-protein adduct formation and superoxide scavenging. Redox Biology, 13, 588-593.

https://doi.org/10.1016/j.redox.2017.07.018

\section{Copyrights}

Copyright for this article is retained by the author(s), with first publication rights granted to the journal.

This is an open-access article distributed under the terms and conditions of the Creative Commons Attribution license (http://creativecommons.org/licenses/by/4.0/). 